\title{
Nausea and vomiting masquerading heart cancer
}

\author{
Joshua S. Shapiro ${ }^{1}$, Vlad C. Vasile ${ }^{1}$, Kyle W. Klarich*2, Hartzell V. Schaff ${ }^{3}$ \\ ${ }^{1}$ Department of Internal Medicine, Mayo Clinic, Rochester, Minnesota, United States \\ ${ }^{2}$ Division of Cardiovascular Diseases, Mayo Clinic, Rochester, Minnesota, United States \\ ${ }^{3}$ Division of Cardiovascular Surgery, Mayo Clinic, Rochester, Minnesota, United States
}

Received: May 12, 2016

DOI: $10.5430 /$ jst.v6n2p62

\author{
Accepted: July 6, 2016 \\ Online Published: July 18, 2016 \\ URL: http://dx.doi.org/10.5430/jst.v6n2p62
}

\begin{abstract}
Primary cardiac tumors are extremely rare, although only $20 \%$ are malignant. Of the malignant tumors, sarcomas are the most common type and usually present with signs and symptoms of pericardial effusion or tamponade, including dyspnea, chest pain, or syncope. We present the case of a woman with nausea, vomiting, and epigastric pain who eventually received the diagnosis of a large cardiac angiosarcoma. To our knowledge, no case reports have described patients with primary cardiac tumors presenting with nausea and vomiting without cardiac symptoms. Our patient was treated with open heart resection of the tumor and reconstruction of the right atrium with bovine pericardium. This case highlights an atypical presentation of this rare condition and shows the current optimal management.
\end{abstract}

Key Words: Cardiac angiosarcoma, Cardiac malignancy, Cardiothoracic surgery, Oncology, Tamponade

\section{INTRODUCTION}

Primary cardiac tumors are rare, with a frequency of approximately $0.0001 \%$ to $0.0003 \%$ in autopsy studies. ${ }^{[1]}$ Of these neoplasms, only $20 \%$ are malignant, and of the malignant tumors, $75 \%$ are sarcoma subtypes. ${ }^{[2]}$ Metastatic causes for cardiac tumors are far more frequent than for primary cardiac malignancies, with a ratio of approximately $40: 1 .^{[3]}$ Men are affected more frequently than women by angiosarcoma - at a ratio of approximately $3: 1$ - and the right atrium (RA) is the most frequent location. ${ }^{[4]}$ The differential diagnoses for a cardiac mass include atrial myxoma, thrombus, metastatic disease, and primary cardiac malignancy such as angiosarcoma, rhabdomyosarcoma, osteosarcoma, and cardiac lymphoma. ${ }^{[3,5]}$ Herein, we present the case of a woman with nausea, vomiting, and epigastric pain who eventually received the diagnosis of a large cardiac angiosarcoma. To our knowledge, no case reports have described patients with primary cardiac tumors presenting with nausea and vomiting without cardiac symptoms.

\section{CASE PRESEntation}

A 60-year-old woman presented to a local emergency department (ED) with 7 days of epigastric pain and nonbloody, nonbilious emesis. In the ED, computed tomography (CT) of the abdomen showed no gastrointestinal pathologic findings but instead a large pericardial effusion. The patient was discharged home with pain medications and an appointment for outpatient cardiology follow-up.

The day after discharge from her local ED, the patient presented to another ED with new shortness of breath, subjective abdominal distension, and worsening epigastric pain and nausea. Transthoracic echocardiography showed a moderate pericardial effusion with tamponade physiology and an estimated left ventricular ejection fraction of $63 \%$. A pericar-

*Correspondence: Kyle W. Klarich, MD; Email: klarich.kyle@mayo.edu; Address: Division of Cardiovascular Diseases, Mayo Clinic, 200 First St SW, Rochester, MN 55905, Minnesota, United States. 
diocentesis was performed, resulting in removal of $500 \mathrm{ml}$ of bloody fluid and marked symptomatic improvement, but cytologic analysis was negative. CT was repeated of chest, abdomen, and pelvis and showed a heterogeneous, complex density along the right lateral margin of the cavoatrial junction of the RA.

The patient was admitted to the hospital, and subsequent positron emission tomography (PET) showed that the mass was hypermetabolic. Transthoracic echocardiography confirmed the presence of a $6 \mathrm{~cm} \times 3 \mathrm{~cm}$ RA free wall mass that was nonobstructive and extended to the superior vena cava and inferior vena cava. She was transferred to our institution for further treatment. On presentation at our institution, the patient was in no acute distress. Her physical examination was remarkable solely for mild sinus tachycardia.

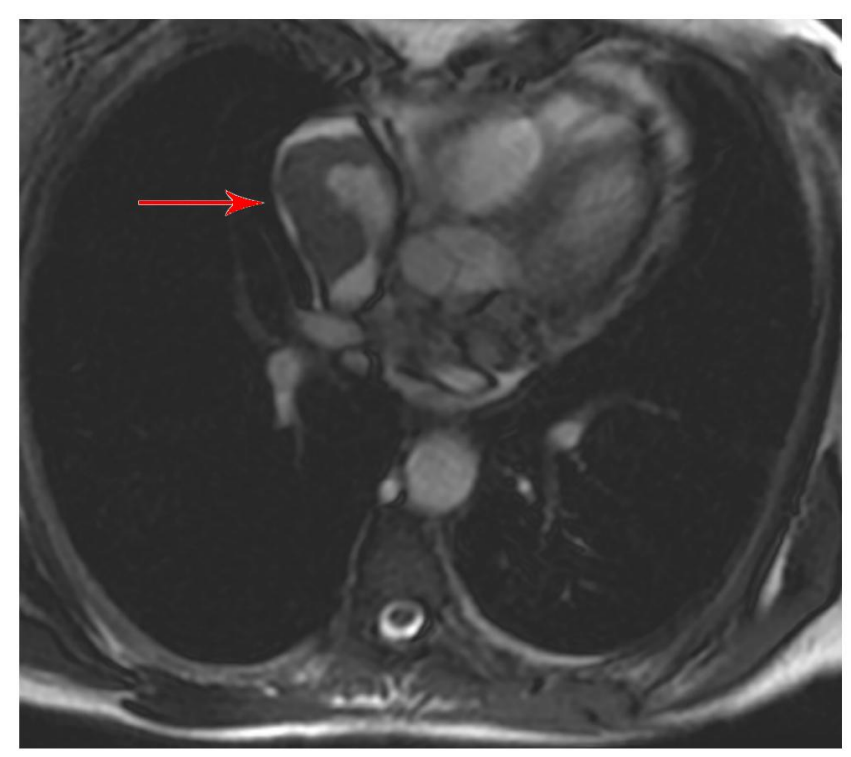

Figure 1. A heterogenous, nonobstructive mass within the right atrium. Magnetic resonance imaging of the heart showed a mass (arrow) extending along the posterior and posterolateral wall from the inferior right atrium near the inferior vena cava-right atrium junction to the superior aspect of the right atrium and filling the right atrial appendage. First-pass perfusion imaging showed mild perfusion of the mass. A moderate, patchy myocardial delayed enhancement was seen. No mediastinal or hilar adenopathy or additional masses were noted.

Cardiac magnetic resonance imaging confirmed the presence of a mass contained within the RA and completely filling the RA appendage (see Figure 1). The mass showed perfusion and delayed enhancement. Electrocardiography showed sinus tachycardia (heart rate, 95 beats per minute). Of note, the patient continued to have tachycardia throughout her admission, perhaps because of the proximity of the mass to the

Published by Sciedu Press sinoatrial node. A biopsy of the RA mass was performed through right heart catheterization with intracardiac echocardiographic guidance. Six tissue specimens were obtained and showed myocardium with inflammatory infiltrate without evidence of lymphoma. We deemed these findings insufficient for diagnosis. A multidisciplinary discussion with cardiac surgery, oncology, and cardiac pathology services and the patient resulted in a decision to remove the mass surgically for diagnostic and therapeutic purposes. No metastatic disease had been identified to date by investigations, including PET.

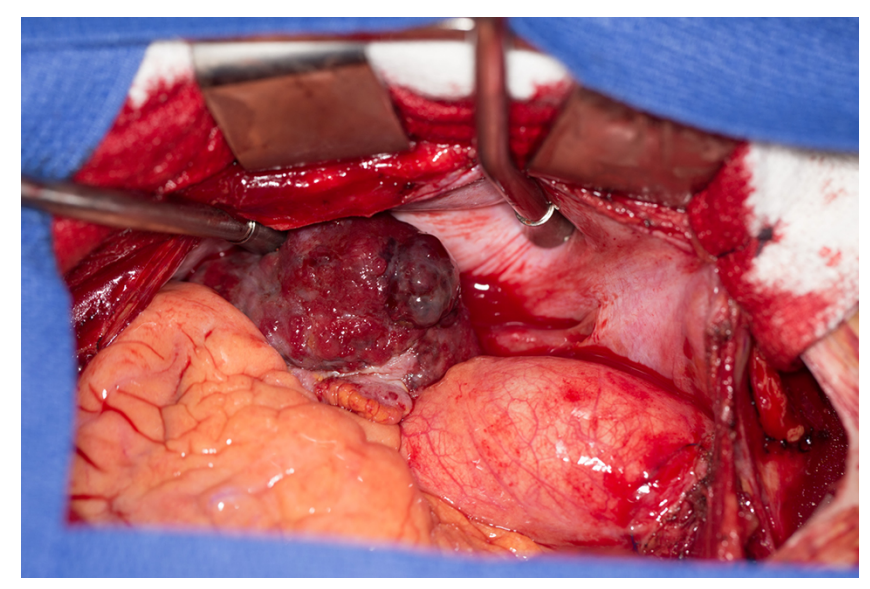

Figure 2. Intraoperative image of primary median sternotomy with the pericardium opened in the midline. A mass was present in the free wall of the right atrium and extended from superior vena cava to inferior vena cava.

On hospital day 5, the patient underwent open heart surgery. After a primary median sternotomy, the pericardium was opened in the midline and a mass was noted in the free wall of the RA, extending from the superior vena cava to the inferior vena cava. It protruded from the mid portion of the free wall of the RA and extended posteriorly to the interatrial groove. However, it did not involve the septum. The tumor margins came close to the right atrioventricular groove. The surgical findings were entirely typical for angiosarcoma (see Figure 2).

The superior vena cava was cannulated near the innominate vein. Bypass was instituted on a single cannula, and an inferior vena caval cannula was placed in the inferior vena cava at the diaphragm while a tack vent was placed on aspiration in the ascending aorta. The cavae were snared around the cannulas, and the operation was performed with the heart beating. 


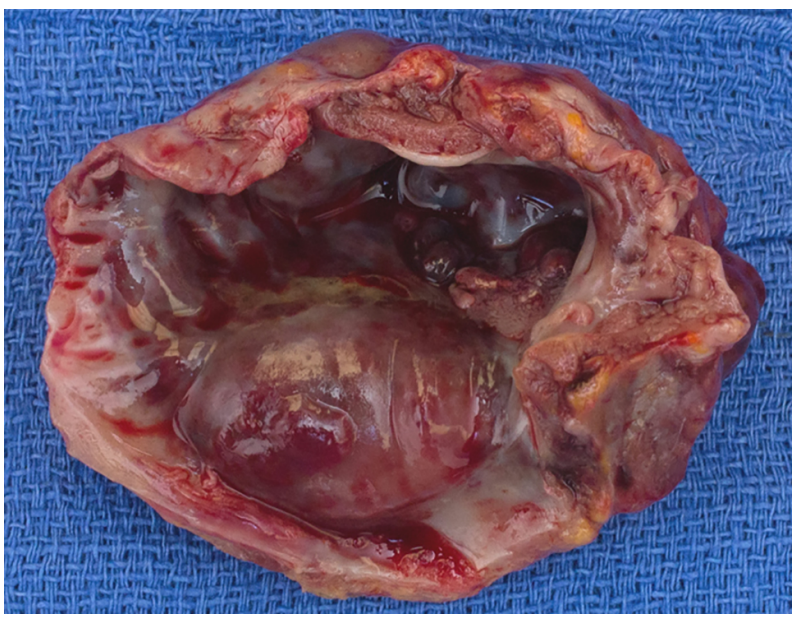

Figure 3. Gross pathologic specimen showing a variegated mass. The mass $(5.8 \mathrm{~cm} \times 5.3 \mathrm{~cm} \times 2.0 \mathrm{~cm})$ involved primarily the right atrial free wall. The tumor was $0.4 \mathrm{~cm}$ from the nearest resection margin. Serial sectioning showed transmural neoplastic involvement. Immunoperoxidase studies showed that the neoplastic cells were strongly reactive, with antibodies directed against CD31 and FLI-1.

The free wall of the RA was excised from the cavoatrial junction superiorly to inferiorly. The mass excision extended anteriorly to a point near the atrioventricular groove and posteriorly to the septum. The atrial septum was left intact, and clear margins were obtained. A large piece of bovine pericardium was fashioned to the correct proportions and sewn to the heart to replace the removed free wall of the RA. Two pacing wires were attached to the superior vena cava near the sinoatrial node and paced at 90 beats per minute. The pathologic examination of the surgical specimen was consistent with high-grade angiosarcoma (see Figure 3). The pacemaker wires were removed on postoperative day 3 . The patient was discharged on postoperative day 7 with a scheduled outpatient follow-up with cardiology and oncology services.

\section{Discussion}

Primary cardiac angiosarcomas (PCAs) often present with dyspnea, chest pain, syncope, hemoptysis, or even cardiac arrest. ${ }^{[4]}$ Frequently, patients present with symptoms of pericardial effusion or tamponade because as the tumor rapidly grows into the myocardium, it tends to bleed. ${ }^{[6,7]}$ When pericardiocentesis is performed, cytologic examination is often negative ${ }^{[4,8,9]}$ PCAs are highly aggressive tumors, with approximately $66 \%$ to $89 \%$ metastatic at diagnosis. ${ }^{[10]}$ When they are metastatic, the presenting symptoms may be related to the metastatic burden of the organ systems.
Echocardiography is generally considered the best initial test for cardiac masses because of its cost-effective accuracy in detecting them ${ }^{[9,11]}$ But cardiac magnetic resonance imaging provides the most comprehensive evaluation, with superior soft tissue detail and tissue characterization. ${ }^{[5]}$ If echocardiography is done with gadolinium-based contrast medium, the vascularity of the tumor can also be assessed. ${ }^{[5]}$ Further work-up may include PET to evaluate for metastases. Tissue specimens may be obtained with echocardiography-guided or CT-guided biopsy, although tissue specimens can frequently be nondiagnostic and the biopsy carries a substantial risk of RA rupture. ${ }^{[12]}$ Because of this risk, when the tumor is consistent with PCA and when other diseases in the differential diagnosis have been ruled out, a decision to go directly to surgical resection before having definitive tissue diagnoses may be appropriate, which it was in our case.

The optimal treatment of patients with these cancers is unclear. For patients with nonmetastatic disease, complete surgical resection is associated with an approximate 11- to 15month survival benefit. ${ }^{[13]}$ Furthermore, surgery is typically well tolerated with minimal morbidity and mortality rates, whereas death is largely linked to the histologic characteristics of the tumor. ${ }^{[14]}$ Unfortunately, adjuvant chemotherapy in patients undergoing surgical resection does not significantly alter the disease course. ${ }^{[13,15,16]}$ Chemotherapy has been used when total resection is unable to be performed or when metastatic disease is present, but responses are shortlived. Common regimens include ifosfamide and doxorubicin or mitomycin, doxorubicin, cisplatin, and paclitaxel. ${ }^{[16]}$ In cases of metastatic disease, chemotherapy is palliative. Because of the rareness of the disease, large trials examining the use of adjuvant therapy for PCAs are currently lacking. Prognosis is poor (mean survival, 5.0-26.6 months) in studies assessing PCAs treated with combination surgery and chemotherapy. ${ }^{[13,17]}$

Our patient initially presented with nausea and vomiting without cardiac symptoms. We suspect that the tumor location might have induced autonomic symptoms secondary to its proximity to the sinoatrial node and thus the atypical presentation with gastrointestinal manifestations. Otherwise, her gastrointestinal symptoms may have been related to the large pericardial effusion compressing local structures, including the stomach and the phrenic nerve. ${ }^{[18]}$

\section{CONFlicts OF INTEREST Disclosure}

The authors declare that there is no conflict of interest statement. 


\section{REFERENCES}

[1] Blackmon SH, Reardon MJ. Surgical treatment of primary cardiac sarcomas. Tex Heart Inst J. 2009; 36(5): 451-2. PMid:19876427.

[2] Bakaeen FG, Reardon MJ, Coselli JS, et al. Surgical outcome in 85 patients with primary cardiac tumors. Am J Surg. 2003 Dec; 186(6): 641-7. PMid:14672772. http://dx.doi.org/10.1016/j.amjsu rg. 2003.08.004

[3] Sparrow PJ, Kurian JB, Jones TR, et al. MR imaging of cardiac tumors. Radiographics. 2005 Sep-Oct; 25(5): 1255-76. PMid:16160110. http://dx.doi.org/10.1148/rg. 255045721

[4] Look Hong NJ, Pandalai PK, Hornick JL, et al. Cardiac angiosarcoma management and outcomes: 20-year single-institution experience. Ann Surg Oncol. 2012 Aug; 19(8): 2707-15. Epub 2012 Apr 3. PMid:22476752. http://dx.doi .org/10.1245/s10434-012 $-2334-2$

[5] Holloway BJ, Agarwal PP. AJR teaching file: Right atrial mass in a woman with dyspnea on exertion. AJR Am J Roentgenol. 2009 Mar; 192(3 Suppl): S49-52. PMid:19234289. http://dx . doi .org/10. 2214/AJR.07.7066

[6] Oshima K, Ohtaki A, Kano M, et al. Primary cardiac angiosarcoma associated with cardiac tamponade: case report. Jpn Circ J. 1999 Oct; 63(10): 822-4. PMid:10553930. http://dx.doi.org/10.12 $53 / j c j .63 .822$

[7] Antonuzzo L, Rotella V, Mazzoni F, et al. Primary cardiac angiosarcoma: a fatal disease. Case Rep Med. 2009; 2009: 591512. Epub 2009 Aug 20. http://dx.doi.org/10.1001/archsurg.1942 .01210240043003

[8] Kupsky DF, Newman DB, Kumar G, et al. Echocardiographic features of cardiac angiosarcomas: the Mayo Clinic experience (19762013). Echocardiography. 2016 Feb; 33(2): 186-92. Epub 2015 Oct 13. PMid:26460068. http://dx.doi.org/10.1111/echo.1306 0

[9] Randall MB, Geisinger KR. Angiosarcoma of the heart: pericardial fluid cytology. Diagn Cytopathol. 1990; 6(1): 58-62. http: //dx.doi.org/10.1002/dc. 2840060113
[10] Janigan DT, Husain A, Robinson NA. Cardiac angiosarcomas: a review and a case report. Cancer. 1986 Feb 15; 57(4): 852-9. http://dx.doi.org/10.1002/1097-0142(1986 0215) $57: 4<852::$ AID-CNCR2820570428>3.0.CO;2-S

[11] Kosuga T, Fukunaga S, Kawara T, et al. Surgery for primary cardiac tumors: clinical experience and surgical results in 60 patients. $\mathrm{J}$ Cardiovasc Surg (Torino). 2002 Oct; 43(5): 581-7.

[12] Brandt RR, Arnold R, Bohle RM, et al. Cardiac angiosarcoma: case report and review of the literature. Z Kardiol. 2005 Dec; 94(12): 8248. PMid:16382384. http://dx.doi.org/10.1007/s00392-005 -0296-0

[13] Simpson L, Kumar SK, Okuno SH, et al. Malignant primary cardiac tumors: review of a single institution experience. Cancer. 2008 Jun; 112(11): 2440-6. PMid:18428209. http://dx.doi.org/10.1002 /cncr. 23459

[14] Herrmann MA, Shankerman RA, Edwards WD, et al. Primary cardiac angiosarcoma: a clinicopathologic study of six cases. J Thorac Cardiovasc Surg. 1992 Apr; 103(4): 655-64. PMid:1548908.

[15] Putnam JB Jr, Sweeney MS, Colon R, et al. Primary cardiac sarcomas. Ann Thorac Surg. 1991 Jun; 51(6): 906-10. http://dx. doi .org/10.1016/0003-4975(91)91003-E

[16] Donsbeck AV, Ranchere D, Coindre JM, et al. Primary cardiac sarcomas: an immunohistochemical and grading study with long-term follow-up of 24 cases. Histopathology. 1999 Apr; 34(4): 295-304. PMid:10231396. http://dx.doi.org/10.1046/j.1365-2559. $1999.00636 . x$

[17] Llombart-Cussac A, Pivot X, Contesso G, et al. Adjuvant chemotherapy for primary cardiac sarcomas: the IGR experience. Br J Cancer. 1998 Dec; 78(12): 1624-8. PMid:9862574. http://dx.doi.org/1 $0.1038 / \mathrm{bjc} .1998 .733$

[18] Khandaker MH, Espinosa RE, Nishimura RA, et al. Pericardial disease: diagnosis and management. Mayo Clin Proc. 2010 Jun; 85(6): 572-93. PMid:20511488. http://dx.doi.org/10.4065/mcp. 2 010.0046 